\title{
The Specification of Hydrological Model Requirements for Bog Restoration
}

\author{
Oskars JAVA \\ Faculty of Engineering, Vidzeme University of Applied Sciences, \\ Cēsu iela 4, Valmiera, LV - 4201, Latvija \\ oskars.java@va.1v
}

\begin{abstract}
Within the scope of biodiversity and sustainable ecosystem development, the restoration of a bog`s ecosystem is important because by reducing the drainage effect on the bog, the negative impact on adjacent intact or relatively intact raised bog and other wetland hydrological regime is lowered. Degraded bogs are mires with a disturbed natural hydrological regime, or those partly exploited for peat extraction. However, the hydrological regime can be restored and peat formation is expected within 30 years. The restoration of a bog`s hydrological regime can be accelerated by filling up the drainage ditches. In the course of researching scientific literature, the author has found no evidence of a system dynamics model developed to simulate tree cutting intensity in degraded bogs after filling the drainage ditches for the purpose of speeding up the restoration of hydrological regime. Developing system dynamics model to calculate tree cutting intensity is an innovative way of solving the problem. Specification requirement technique is a useful tool for determining the elements that shape a bog`s hydrological system and interact with each other, thus providing the design for a simulation model. The next step of the research, following the specification of the requirements, will be the development and verification of the simulation model using real life data.
\end{abstract}

Keywords: requirement specification, object-oriented analysis and design, simulation modelling, bog restoration, input data

\section{Introduction}

Restoration of hydrological regime will simultaneously improve ecosystem functions of whole bog`s nature reserve, it will delay fast growing of trees and will ensure formation of peat soil - processes that are characteristic to habitat and have been partly or completely stopped due to changes in the hydrological regime (Institute for Environmental Solutions, 2014)

Experimentation with forest thinning intensity in real life would take years to establish the optimal scale of intervention into the ecosystem - intensity of thinning out in order to reach the desired result by cutting down as few trees as possible - to increase saturation of soil with water that would contribute to resurgence of the bog and bog forest biotopes. This is the reason why system dynamics modelling was chosen to solve this problem, because it allows to predict the tree cutting influence on the ecosystem without expensive and time-consuming experiments in the real life. 
Bog hydrological system is a complex system with many components, thus specification requirement technique is a useful tool to determine the elements that shape bog ecosystem and interact with each other before building model.

\section{Requirements specification}

There are socio-technical requirement specification methods like Socio-technical toolbox (STT), Socio-technical System engineering (STSE), Soft System Methodology (SSM), Object-Oriented Analysis and Design (OOAD), Agile Systems development, Cognitive Engineering, Contextual Design, System Thinking, Cognitive Work Analysis, Human Centred Design, Effective Technical and Human Implementation of Computer-supported Systems (ETHICS) format.

In authors opinion the most suitable specification requirement tool to determine components forming the bog hydrological system is (OOAD), because it is applicable both in system dynamics and object modelling systems. Based on OOAD it will be able to build system dynamics model in STELLA system dynamics system and JupyterLab software, which is based on object modelling system framework.

OOAD principles are fundamentally based on real world objects (Powell-Morse, 2017) in this case the elements forming the bog hydrological system.

As a wetland modelling specialist Jørgensen mentioned in his previous work, to administer bog ecosystems decently and to optimize their role in the landscape, it is crucial to understand how these systems act and what to await when we intervene or change the way they are. We must clearly understand how by changing one part of a bog we influence the other parts of ecosystem (Jørgensen et al., 1988).

OOAD combine all behaviours, characteristics and states together into one analysis process, rather than splitting them up into separate stages, as many other methodologies would do (Powell-Morse, 2017).

OOAD can be divided in two parts - Object-Oriented Analysis (OOA), and ObjectOriented Design (OOD). The products of OOA serve as the models from which we may start an object-oriented design; the products of OOD can then be used as blueprints for completely implementing a system using Object-Oriented Programming (OOP) methods (Booch, 1998).

\section{Object-Oriented Analysis}

The primary tasks of OOA are:

1. Identifying objects;

2. Organizing the objects by creating object model diagram;

3. Defining the internals of the objects, or object attributes;

4. Defining the behaviour of the objects, i.e., object actions;

5. Describing how the objects interact (WEB, a).

In the study of the boundaries of the bog hydrological model the theoretical methods as case study and content analysis, specifically evaluative, explorative and instrumental review methods were mainly used. 


\subsection{Objects}

Objects forming the hydrological system of the bog can be divided in classes:

Geological objects: Peat layer, Till layer, Shale layer, Lake, Channel;

Biological objects: Forest tree stand;

Process objects: Interception, Sublimation, Evaporation, Lake evaporation, Infiltration, Lateral flow, Percolation, Overland flow, Lake outflow;

Meteorological objects: Precipitation, Wind speed, Solar radiation, Air temperature, Relative humidity.

\subsection{Object model diagram}

Model diagram of the bog hydrological system including all objects is shown in Fig. 1 and processes explained in section 3.3.

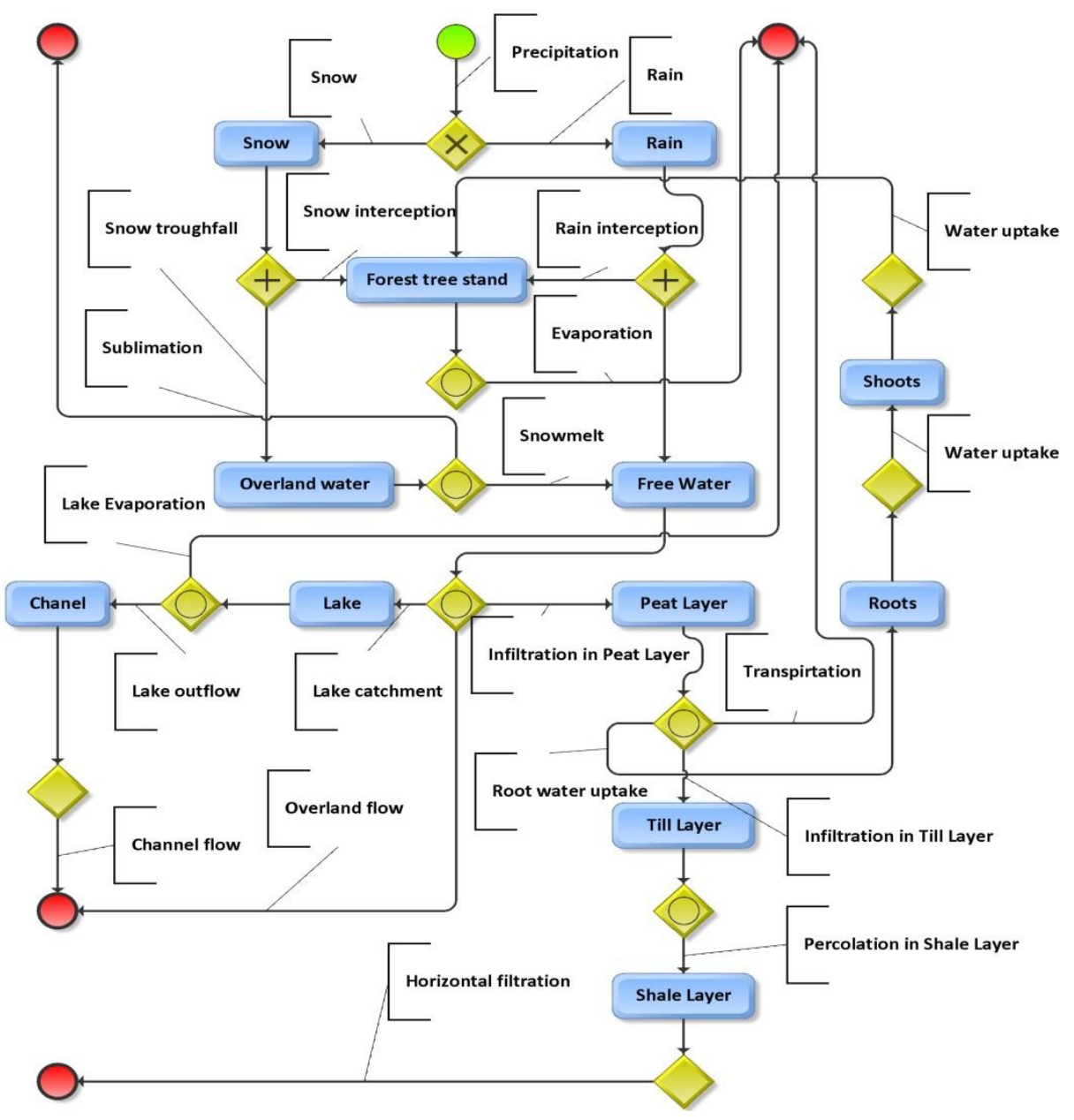

Figure 1. Bog hydrological system diagram 


\subsection{Object attributes and actions}

The main object attributes and actions of bogs`ecosystem model are:

Interception is a function that calculates the volume of precipitation cached by forest tree stands.

Tree crown structure and size determines how many percent of the total precipitation does not reach the ground. In Baltic States bog forests pine tree is widespread, but coniferous forest lets less water through its canopy as the deciduous forest. The reason for that is the four-sided shape of needle that allows to capture water at needle tips in form of droplets, while it flows down of flat wet leaves relatively easily. Furthermore, coniferous tree will have greater needle amount compared to leaves of deciduous tree of the same size (Klamerus-Iwan, 2014).

Coniferous trees contrary deciduous trees do not drop leaves, therefore high interception rate persists also during the winter time, which lets intercepted snow to sublimate.

As showed research "Influence of tree transpiration on mass water balance of mixed mountain forests of the West Carpathians", 20 percent of precipitation are intercepted and does not reach the ground, but incur back into the atmosphere (Mind'áš J, 2006).

Sublimation is a function how intercepted snow leaves the tree crown in form of vapour overleaping melting process.

Snow sublimation from the tree canopy and the ground may increase by the influence of solar radiation and positive air temperature. Sublimation, when knowing the tree crown aerodynamic properties, can be simulated with a simple energy balance model (Andreadis et al., 2009).

Evaporation from trees occurs in vegetation period when plants behave as water pumps, taking water in with their roots, taking it up through the trunk and eventually releasing water vapour through the pores and leaf stomata.

Leaf water evaporation into the surrounding atmosphere depends on tree species and ambient atmospheric conditions such as vapour pressure, relative humidity, air temperature, and rainfall, which is why these parameters should be included in evaporation calculations (Leininger et al., 2016).

Based on detailed information of vegetation structure, model should include the appropriate parameters corresponding to tree physical properties, such as the canopy storage capacity and the total evaporation capacity (Carey et al., 2009).

Evaporation from forest is higher than from intact swamp. This is caused by higher interception of forest tree stands and higher evaporation rate resulting from the several times higher leaf area index compared to sphagnum moss.

Evaporation is determined not only by the meteorological conditions and climate factors, but also by tree biological factors, influencing tree crown irradiance and shading. That is why while constructing swamps ecosystem model it is important to collect empirical data regarding tree species and their anatomical and physiological properties.

Leaf area index is the main parameter in scope of bogs hydrological regime restoration. By definition, this is the ratio of one-sided leaf area per unit ground area.

Leaf area index quantifies the amount of leaf material in a canopy normalized by whole stand ground area (Pokorný et al., 2012).

Overland water in comprehension of this study is formed by precipitation falling as snow. When air temperature is below $0^{\circ} \mathrm{C}$ snow sublimates, but when air temperature is above $0^{\circ} \mathrm{C}$ some part of it drains in the peat layer and some part forms overland flow.

Lake evaporation occurs from bog lakes and ponds. 
Evaporation of water from a water surface depends on water temperature, air temperature, air humidity and air velocity above the water surface (The Engineering Toolbox, 2017).

Peat layer and bog in general works as a sponge - it absorbs water in wet conditions, but slowly returns it in dry conditions, thus regulating water level and reducing flood risk.

Infiltration in the peat layer, evaporation, and down-driven water movement are the main factors that influence the humidity change in the peat storage. Before reaching the saturation of the soil, water infiltrates directly in the peat layer. In this case, the infiltration rate of the peat layer is equal to the precipitation intensity. Infiltration capacity is calculated based on the total volume of infiltration (Elshorbagy et al., 2007).

The rate at which water infiltrates into the soil depends on the temperature at the surface and the temperature of the soil.

One of the most important soil properties is the variation in porosity with depth. The soil porosity determines its water holding capacity. Porosity is a function of the size of particles and the way they are arranged. Pore spaces represent the reservoir for holding water and permeability, administrates how quickly water will flow through soil (Lawrence and Jiang, 2017).

Till layer lies underneath the peat layer. In Baltic States till mostly consists of sand and may contain pebble. In the till layer occur process called percolation. Percolation is a process when by the force of gravity, the water held in the pore spaces is moved downward, transforming it from the soil water to the groundwater.

Moisture movement in the till layer depends on the moisture conditions in the overlying peat layer, soil suction in the peat and till layers, soil temperature of the till layer, evapotranspiration from the till layer, and percolation to the underlying shale layer. If the moisture content in the peat layer is less than the wilting point, there is no downward water movement from the peat layer to the till layer. In case of fully saturated soil, when the till layer temperature is greater than $0^{\circ} \mathrm{C}$, water will seep from the peat layer to the till layer. The peat layer will release water only after reaching saturated conditions and there is residual moisture forming. In the case of saturated till layer, water absorption will occur according to the saturated hydraulic conductivity of the till layer. The moisture movement from the peat to the till layer is highly dependent on the moisture contents in both layers (Elshorbagy et al., 2007).

Shale layer lies underneath the till layer. In Baltic States till usually consists of moraine containing clay and sand mixture in different locality blended in different percentage.

Moisture movement in the shale layer depends on gravity forced filtration from the till layer. Water will percolate from the till layer to the underneath located shale layer only when the moisture content in the till layer is greater than the wilting point. In the case of a saturated shale layer, the maximum rate at which the water can be received by the shale layer will conform to the saturated hydraulic conductivity of the shale layer (Elshorbagy et al., 2007).

Overland flow is formed when precipitation in form of rain falls on the ground surface faster than the soil can absorb it, then the water begins to pool up and form a thin film. When overland water capacity is exceeded, overland flow occurs.

Overland flow is computed after the soil moisture demand is satisfied. In the summer water surplus exceeding the peat layer infiltration capacity (when peat layer is saturated) is diverted to overland flow. In frozen conditions, part of the available water from both 
rainfall and snowmelt infiltrates into the frozen soil but the surplus diverts to overland flow (Elshorbagy et al., 2007).

The extent of this runoff flow depends on the amount of water in the overland layer, the slope of the surface and the roughness of the surface that the water flows over. The roughness is a function of the vegetation covering an area.

Lake outflow has a threshold. The outflow ends if the water level drops below the threshold. This is also the lake's start value on the water level (Swedish Meteorological and Hydrological Institute, 2017).

Lake outflow occur through a channel. Lake outflow speed can be determined during empirical observation.

\subsection{Model Input and Output Data}

To run the degraded bog system dynamics model it is necessary to have:

1. Meteorological data:

- $\quad$ Precipitation (rain, snow);

- Wind speed;

- Solar radiation;

- Air temperature;

- Temperature at soil surface;

- Relative humidity.

The meteorological data for the model can be obtained in the form of indirect observations from the geographically closest weather station or collected from weather station located in the bog if available.

2. Geological data:

- Bog slope;

- $\quad$ Lake area and depth;

- Channel width, depth and slope;

- Peat layer, till layer and shale layer depth;

- $\quad$ Peat layer, till layer and shale layer maximum water storage.

The geological data for the model can be derived from the MOSYS data array, whose data is modelled on data from direct observations.

\section{Soil hydraulic properties:}

- Peat layer wetting front suction head;

- Peat, till and shale total porosity;

- Peat, till and shale effective porosity;

- Peat residual saturation;

- Peat saturated hydraulic conductivity.

There are several scientific sources available that describe the hydraulic properties of various mineral and organic soils. Using these studies, it is possible to choose data from the case with most suitable climatic conditions and soil composition. However, in order to obtain the most accurate output data, the input data should also be accurate, so it is recommended to perform laboratory measurements of soil samples. 
4. Remote sensing data:

- Reflectance in near infrared band;

- Reflectance in red band.

The most suitable data for leaf area index calculation is remote sending data in reflectance in near red infrared band and in red band, which can be obtained using the Light Detection and Ranging (LIDAR) sensor.

Remote sensing data for the Swan Island bog case study by the author was derived from indirect observations using the Environmental Solution Institute's Aerodrome Laser Scan (LIDAR) data. If there is no LIDAR data available, it is applicable to use Moderate Resolution Imaging Spectroradiometer (MODIS) satellite data.

5. Values to be calibrated:

- Leaf distribution angle;

- $\quad$ Specific leaf storage;

- Snow interception coefficient;

- Maximum snow storage in the tree canopy;

- Peat evaporation coefficient;

- Till infiltration coefficient;

- Shale infiltration coefficient.

The hydrological model of the bog is significant for obtaining output data that is difficult to measure in real life, as:

- Groundwater level;

- Interception;

- Evaporation;

- Transpiration;

- Overland flow;

- Infiltration in the peat layer.

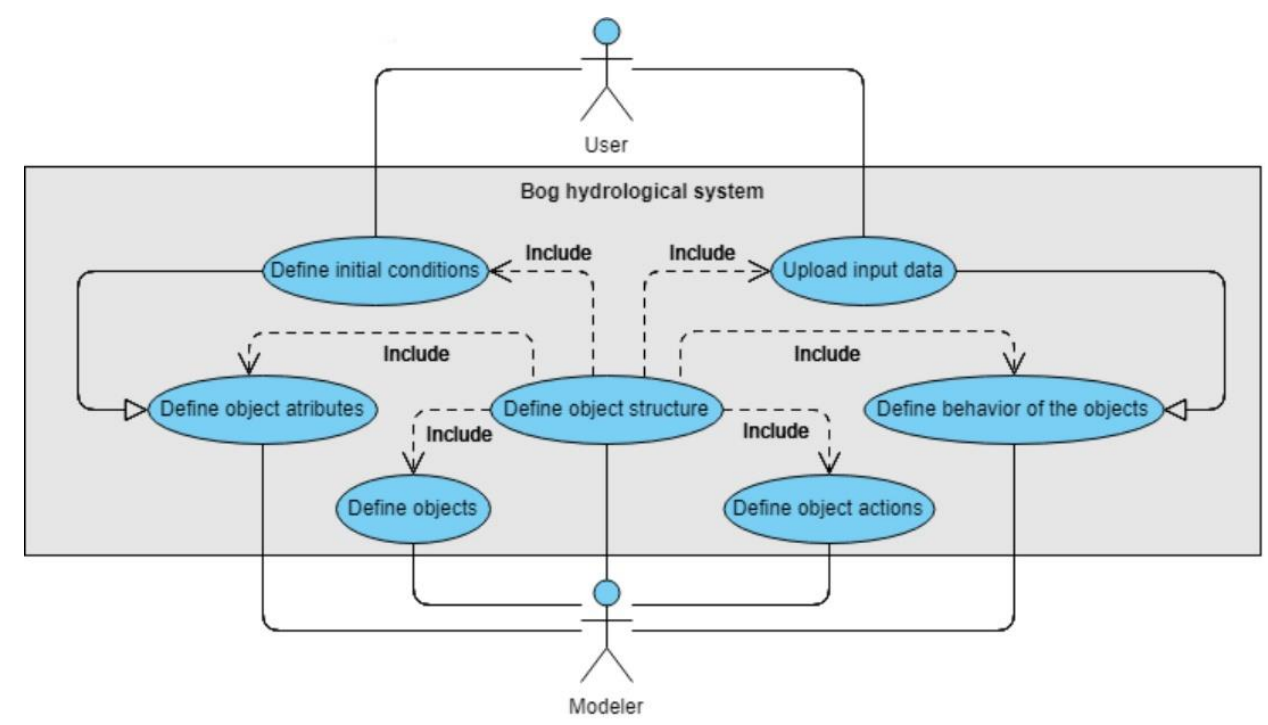

Figure 2. Internal steps of the bog hydrological model UML use case diagram 


\section{Object-Oriented Design}

\begin{tabular}{|c|}
\hline Meteorological data \\
\hline 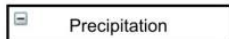 \\
\hline $\begin{array}{l}\text { - date: Date } \\
\text { - rain }(\mathrm{mm}): \text { int } \\
\text { - snow }(\mathrm{mm}) \text { : int }\end{array}$ \\
\hline $\begin{array}{l}\quad \text { Wind speed } \\
\end{array}$ \\
\hline $\begin{array}{l}\text { - date: Date } \\
\text { - speed }(\mathrm{m} / \mathrm{s}) \text { : int }\end{array}$ \\
\hline 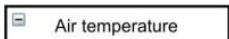 \\
\hline $\begin{array}{l}\text { - date: Date } \\
\text { - temperature (C): int }\end{array}$ \\
\hline$\square$ Soil temperature \\
\hline $\begin{array}{l}\text { - date: Date } \\
\text { - temperature (C): int }\end{array}$ \\
\hline 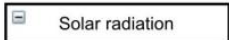 \\
\hline $\begin{array}{l}\text { - date: Date } \\
\text { - cal/d/m2: int }\end{array}$ \\
\hline$\square$ Relative humidity \\
\hline $\begin{array}{l}\text { - date: Date } \\
\text { - relative humidity (\%): int }\end{array}$ \\
\hline
\end{tabular}
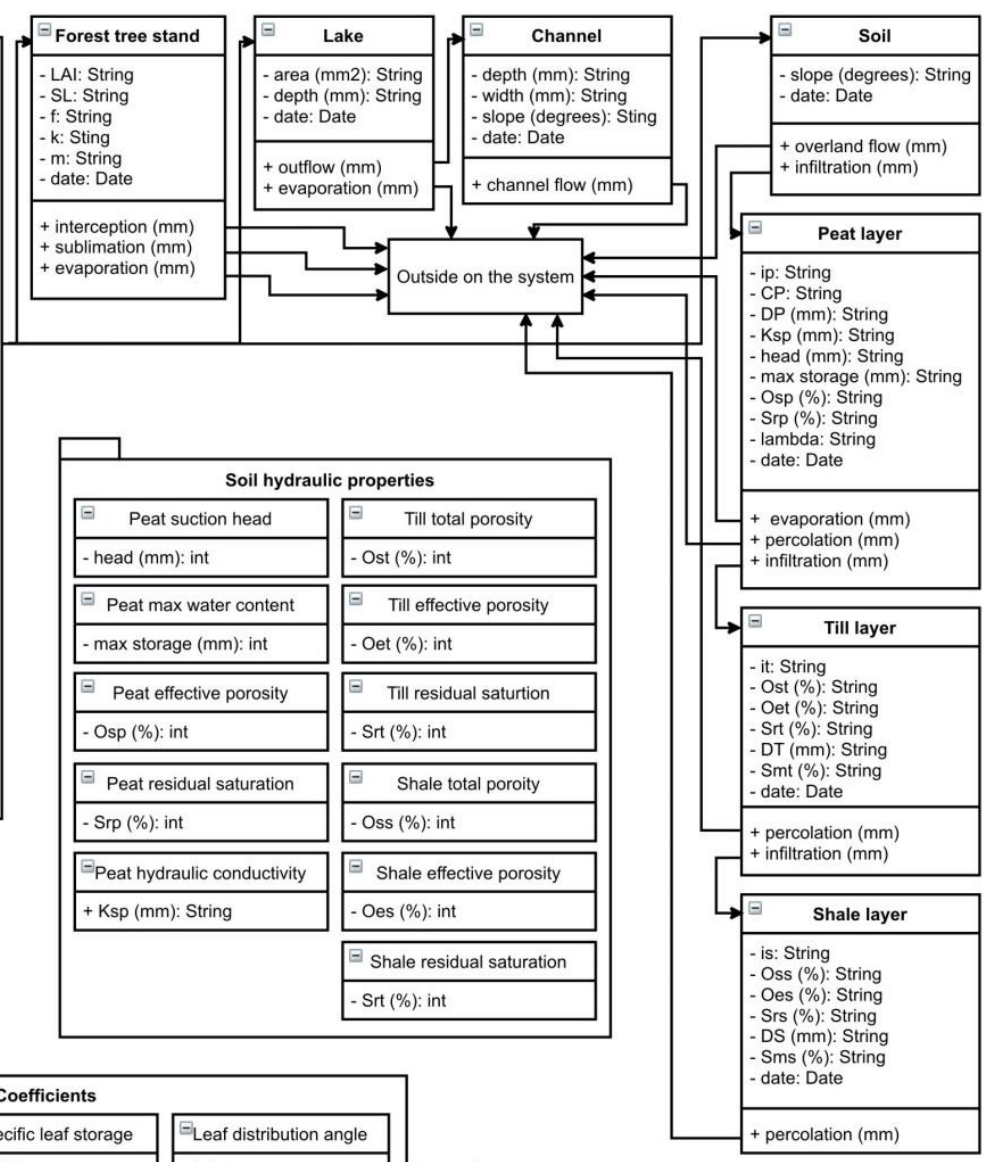

\begin{tabular}{|c|c|c|c|}
\hline \multicolumn{4}{|c|}{ Coefficients } \\
\hline${ }^{E}$ Leaf area index & ${ }^{-}$Specific leaf storage & \multicolumn{2}{|c|}{$E$ Leaf distribution angle } \\
\hline - LAl: int & -SL: int & \multicolumn{2}{|c|}{$-k$ : int } \\
\hline${ }^{\square}$ Max. snow storage & \multicolumn{2}{|c|}{${ }^{\square}$ Snow interception coef. } & $\exists$ Peat lambda \\
\hline$-\mathrm{m}$ : int & \multicolumn{2}{|l|}{-f: int } & - lambda: int \\
\hline Epeat infiltration coef. & \multicolumn{2}{|c|}{ Epeat evaporation coef. } & ${ }^{-}$Till infiltration coef. \\
\hline - ip: int & \multicolumn{2}{|l|}{ - CP: int } & - it: int \\
\hline${ }^{{ }}$Shale infiltration coef & \multicolumn{2}{|c|}{${ }^{-}$Shale infiltration coef. } & \\
\hline - is: int & \multicolumn{2}{|l|}{ - is: int } & \\
\hline
\end{tabular}

\begin{tabular}{|c|c|c|}
\hline \multicolumn{3}{|c|}{ Geological data } \\
\hline E Bog slope & 1 Lake are & $\square$ Channel depth \\
\hline - slope (degrees): int & - area (mm2): int & - depth $(\mathrm{mm})$ : int \\
\hline$\exists$ Peat layer depth & $\square$ Lake depth & $\Xi$ Channel slope \\
\hline - DP (mm): int & + depth $(\mathrm{mm})$ : int & - slope (degrees): int \\
\hline$\square$ Till layer depth & & $\Xi$ Channel widht \\
\hline - DT (mm): int & & - width $(\mathrm{mm})$ : int \\
\hline
\end{tabular}

\begin{tabular}{|c|c|c|c|c|c|}
\hline & & & Output data & & \\
\hline EGroundwater level & Interception & $\Xi \quad$ Evaporation & $\exists$ Transpiration & $\exists \quad$ Percolation & Infiltration moisture deficit \\
\hline $\begin{array}{l}\text { + water }(\mathrm{mm}) \text { : String } \\
\text { - date: Date }\end{array}$ & $\begin{array}{l}\text { + water }(\mathrm{mm}) \text { : String } \\
\text { - date: Date }\end{array}$ & $\begin{array}{l}\text { + water }(\mathrm{mm}) \text { : String } \\
\text { - date: Date }\end{array}$ & $\begin{array}{l}\text { + water }(\mathrm{mm}) \text { : String } \\
\text { - date: Date }\end{array}$ & $\begin{array}{l}\text { + water }(\mathrm{mm}) \text { : String } \\
\text { - date: Date }\end{array}$ & $\begin{array}{l}\text { + water }(\mathrm{mm}) \text { : String } \\
\text { - date: Date }\end{array}$ \\
\hline$\exists$ Channel flow & Sublimation & Infiltration & $\exists$ Overland flow & \multicolumn{2}{|c|}{${ }^{\Xi}$ Cumulative volume of infiltration } \\
\hline $\begin{array}{l}\text { + water }(\mathrm{mm}) \text { : String } \\
\text { - date: Date }\end{array}$ & $\begin{array}{l}\text { + water }(\mathrm{mm}) \text { : String } \\
\text { - date: Date }\end{array}$ & $\begin{array}{l}\text { + water }(\mathrm{mm}) \text { : String } \\
\text { - date: Date }\end{array}$ & $\begin{array}{l}\text { + water }(\mathrm{mm}) \text { : String } \\
\text { - date: Date }\end{array}$ & \multicolumn{2}{|l|}{$\begin{array}{l}\text { + water }(\mathrm{mm}) \text { : String } \\
\text { - date: Date }\end{array}$} \\
\hline
\end{tabular}

Figure 3. Bog model design UML class diagram 
Object-Oriented Design (OOD) involves implementation of the conceptual model produced during OOA, in other words, OOD is detailed description of how the system is to be built on concrete technologies (WEB, a).

The STELLA system dynamics system and Python programming language are closed dynamic systems. These simulation models will be made to represent water movement in bog hydrological system from water input through precipitation to water output through interception, sublimation, evaporation, transpiration, lake outflow and overland flow.

The input data will be loaded manually from QGIS Open Source Geographic Information System and Excel databases. It will be possible to generate output data in form of frequency tables, graphical analysis, review tables, GIS raster files and other.

How user and modeller interact with the bog hydrological model, and inner parts of the model interacts with each other are shown in Fig. 2.

Spatial representation of bog hydrological model is shown in Fig. 1 and objects, object attributes, object actions and object behaviour described in section 2.3.

As in the dynamic system in the hydrological system of the bog, the flow of water from one class to another takes place based on mutual causal relationship. In the Figure 3 all the objects of the bog hydrological model are visualized in classes. All the input data is divided in classes based on affiliation to meteorological data, geological data, soil hydraulic properties and coefficients.

The objects which are receiving, holding and passing on the water are forest tree stand, lake, channel, soil (peat layer, till layer, shale layer). The water movement in these elements is represented with arrows. Each element uses input data as attributes and reflects changes in water content as operations that are defined as output data.

\section{Conclusions and discussion}

Tree determination of tree thinning intensity in degraded bogs using modelling is a new innovative approach which should allow the water level of ecosystems to be restored faster and more efficient, thus increasing natural diversity, improving the quality of life of local people and promoting bog recreational ability.

This study helped to understand complex interrelationships that exist between different elements within a bog hydrological system. The bog hydrological system boundaries are clarified, and the specification requirements determined. The next step is, using object-oriented programming (OOP), translate OOD into mathematical equations to develop simulation models in STELLA system dynamics system and Python programming language and compare the performance.

As in STELLA system dynamics system it is possible to develop user interface, which is easy usable for users without specific programming knowledge, the author sees this model as a tool for decision makers. Decision makers will be able to easily upload necessary input data and by changing LAI observe how it interacts with changes in groundwater level. Python user must have programming prerequisites, thus narrowing down the potential number of users, but at the same time it allows to run several statistical analyses and visualize data, which is not possible in STELLA. 


\section{References}

Andreadis, K.M., Lettenmaier, D.P., Storck, P. (2009). Modeling snow accumulation and ablation processes in forest environments. Water Resources Research, 45. 1-13. DOI: 10.1029/2008WR007042

Booch, G. (1998). Object-oriented analysis and dedign with applications. 2nd ed. Addision Wesly, California

Carey, S., Elshorbagy, A., Kesha, N. (2009). A generic system dynamics model for simulating and evaluating the hydrological performance of reconstructed watersheds. Hydrology and Earth System Sciences. 13. 865-881. DOI: 10.5194/hess-13-865-2009

Elshorbagy, A., Julta, A., Kells, J. (2007). Simulation of the hydrological processes on reconstructed watersheds using system dynamics. Hydrological Sciences Journal. 52(3). 538-562. DOI: 10.1623/hysj.52.3.538.

Institute for Environmental Solutions. (2014). Restoration of the hydrological regime in marshy forests in the nature reserve of Gulbjusala bog. (in Latvian). Preprint, available at https://forrest.daba.gov.lv/ upload/File/Gulbju_salas_programma.pdf

Jørgensen, S.E., Mitch, W.J., Straškraba, M. (1988). Wetland Modelling. Developments in Environmental Modelling. 12, 1-8.

Klamerus-Iwan, A. (2014). Different views on tree interception process and its determinants. Forest Research Papers. 75(3). 291-300. DOI: 10.2478/frp-2014-0028

Lawrence, M., Jiang, Y. (2017). Porosity, Pore Size Distribution, Micro-structure. Bio-aggregates Based Building Materials. RILEM State-of-the-Art Reports 23, 39-71. DOI: 10.1007/97894-024-1031-0_2

Leininger, T.D., Ouyang, Y., Xu, D., Zhang, N. (2016). A system dynamic model to estimate hydrological processes and water use in a eucalypt plantation. Ecological Engineering. 86. 290-299. DOI: 10.1016/j.ecoleng.2015.11.008

Mind'áš J., Škvarenina J., Střelcová K. (2006). Influence of tree transpiration and mass water balance of mixed mountain forests of the West Carpathians. Biologia. 61(19). 305-310. DOI: 10.2478/s11756-006-0178-6

Pokorný, R., Stroḷič, S. (2012). Leaf area index of Norway spruce stands in relation to age and defoliation. Berskydy. 5(2). 173-180.

Powell-Mors, A. (2017). Object-Oriented Analysis and Design: What it is and how do you use it? available at https://airbrake.io/blog/design-patterns/object-oriented-analysis-and-design

Swedish Meteorological and Hydrological Institute. (2017). Rivers and lakes, available at http://www.smhi.net/hype/wiki/doku.php?id=start:hype_model_description:hype_routing

The Engineering Toolbox. (2017). Evaporation from Water Surfaces, available at http://www.engineeringtoolbox.com/evaporation-water-surface-d_690.html

WEB (a). OOAD - Object Oriented Paradigm. https://www.tutorialspoint.com/object_oriente d_analysis_design/ooad_object_oriented_paradigm.htm

\section{Authors' information}

Oskars Java received the master's degree in computer sciences in the field of Information Technology (System Analysis, Modelling and Design subsector) in year 2017. Author is proceeding $\mathrm{PhD}$ studies in the field of Information Technologies at Vidzeme University of Applied Sciences. 